\title{
Assessment of the Accuracy of Cable Sheath Fault Location Device and Enhancement of its Performance
}

\author{
Niall Kennedy \\ Technological University Dublin, niall.kennedy7@mydit.ie \\ Joseph Kearney \\ Technological University Dublin, joseph.kearney@tudublin.ie \\ Tom Looby \\ ESB Networks Ireland, Tom.Looby@esb.ie
}

See next page for additional authors

Follow this and additional works at: https://arrow.tudublin.ie/engscheleart

Part of the Computational Engineering Commons

\section{Recommended Citation}

Kennedy, N. et al. (2018) Assessment of the Accuracy of Cable Sheath Fault Location Device and Enhancement of its Performance , 53rd International Universities Power Engineering Conference, 4th-7th September 2018, Glasgow, Scotland.

This Conference Paper is brought to you for free and open access by the School of Electrical and Electronic Engineering at ARROW@TU Dublin. It has been accepted for inclusion in Conference papers by an authorized administrator of ARROW@TU Dublin. For more information, please contact arrow.admin@tudublin.ie, aisling.coyne@tudublin.ie,gerard.connolly@tudublin.ie.

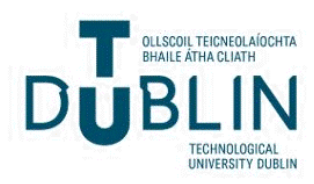


Authors

Niall Kennedy, Joseph Kearney, Tom Looby, and Ciaran O'Leary

This conference paper is available at ARROW@TU Dublin: https://arrow.tudublin.ie/engscheleart/296 


\section{Assessment of the Accuracy of Cable Sheath Fault Location Device and Enhancement of its Performance}

\author{
Niall Kennedy \\ Dublin Institute of Technology, \\ Ireland \\ niall.kennedy7@mydit.ie
}

\author{
Dr. Joseph Kearney \\ Dublin Institute of Technology, \\ Ireland \\ joseph.kearney@dit.ie
}

\author{
Mr. Tom Looby \\ ESB Networks, \\ Ireland \\ tom.looby@esb.ie
}

\author{
Mr. Ciaran O'Leary \\ ESB Networks, \\ Ireland \\ ciaran.oleary@esb.ie
}

\begin{abstract}
As power system networks are being constantly upgraded and extended, there is a greater importance in the reliable transmission of electrical power and fault finding techniques, especially for cables installed underground. Damage to a cable's protective sheath can damage a cables life span and also lead to disruption of system operation and loss of supply. This study includes research into the literature and techniques used to locate these faults accurately. Bridge resistance and volt drop measurement techniques are the main methods used by sheath fault location devices to locate faults accurately. This task is made more difficult because such devices are hindered by a limited test current. This study carries out an analysis of the accuracy of a leading cable sheath fault location device, which utilizes the volt drop method. Testing was conducted across a series of circuits and a comparison of accuracy was made between this device and a range of measurement devices. After a thorough analysis of test results was carried out, a new method of sheath fault location was developed and examined with the aim of improving fault location accuracy.
\end{abstract}

Keywords-Cable, Sheath Fault, Accuracy, Installation, VoltDrop, Resistance, Repeatability, Error.

\section{INTRODUCTION}

Standard electrical power cables are designed to consist of several concentric layers enclosing an electrical conductor. The most outer layer of the cable is known as the cable sheath. A cable sheath can be described as a polymer covering, used to prevent the ingress of moisture or dirt. Cable sheath materials most commonly include Polyvinyl Chloride (PVC) and Polyethylene (PE) [1]. A cable fault can be described as any weakness or defect that affects the operational quality of the cable system. Most cable faults can be categorised as contact faults (between phase(s) and earth) or breaks. This study focused on single core cable sheath to ground faults and investigated how these faults are located.

The most effective way of locating cable sheath faults is by using a sheath fault location device. Cable sheath faults for instance are found by using pre-location methods. These methods narrow down the distance to a fault and techniques such as pinpointing and signal trace methods can then be used to determine the exact location of the fault.
The accuracy of sheath fault location can depend on the method of cable installation. When buried directly in soil, sheath fault detection can be quite accurate. However, when installed in underground plastic ducts, the effectiveness of sheath fault location can be reduced [5].

The main aim of this study is to lead to an improvement in the pinpointing of cable sheath faults. By reducing the margin of error in fault pre-location, significant reductions in both cost (due to reduced digging) and fault finding time can be made.

This study will analyse the performance of an industry-leading cable sheath fault location device by conducting tests on circuits and cables of different CSA and length. Simulated sheath faults will vary in magnitude and be placed at predetermined fault locations. Highly accurate test instruments will be used as a comparison to verify the accuracy of the fault location device.

Finally, results obtained using this device will be compared with a proposed improved method of sheath fault location and any improvements will be quantified.

\section{DESIGN PROCESS}

To determine the accuracy of the device under investigation, a series of test circuits were used. These test circuits were designed to act as a representation of underground electrical transmission and distribution installations. A test circuit is required to be able to simulate a cable sheath fault at a known distance, where test results are expected to produce a predetermined outcome. Test circuits must also produce repeatable results.

Benchmark circuits were created using a series of high specification resistors which had the ability to withstand high voltages (up to $10 \mathrm{kV}$ ) and dissipate heat across them.

Two benchmark circuits were used:

- A resistor circuit with a loop resistance of $0.705 \Omega$, representing a $1000 \mathrm{~m} 25 \mathrm{~mm} 2$ cable installation. A fault could be manually placed between these resistors, where the ratio from the fault to each end terminal was $36.4 \%$ and $63.6 \%$.

- A resistor circuit with a loop resistance of $0.07 \Omega$ representing a $1000 \mathrm{~m} 240 \mathrm{~mm} 2$ cable installation. Similarly, a fault could be 
manually placed between these resistors, where the ratio from the fault to each end terminal was $71.4 \%$ and $28.6 \%$.

Testing was also conducted on two cable circuits. These circuits were designed as:

- Four 250m cable coils of A2XCY 1x35mm2 RM/25mm2 GY, connected in series where the $25 \mathrm{~mm} 2$ copper shield was exposed at $250 \mathrm{~m}$ intervals across the $1 \mathrm{~km}$ circuit, allowing for the connection of a simulated sheath fault at a known distance.

- Four $250 \mathrm{~m}$ single core cable coils of YY-SC 1x240mm2 connected in series. Similarly, the copper core was exposed at $250 \mathrm{~m}$ intervals along the circuit to allow for connection of a cable sheath fault.

Total loop resistance was measured accurately at $0.705 \Omega$ and $0.07 \Omega$ respectively. Both cable test circuits are represented by the circuit diagram in Figure 1.

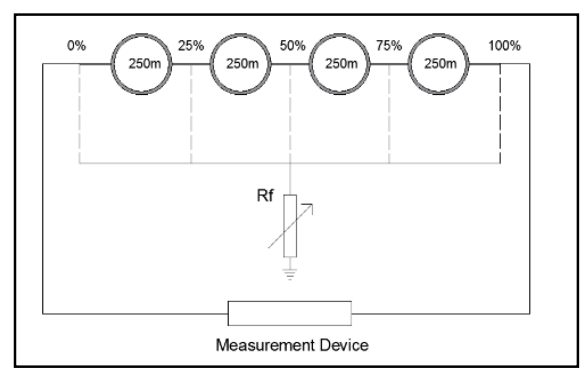

Fig. 1. Cable Circuits Configuration

Two main test instruments were used in the experimental procedure as a comparison to investigate the accuracy of the fault location device. The highly accurate nanovoltmeter was used to measure low noise voltages accurately and an Insulation Resistance Tester (IRT) was used as a constant current source to verify whether low resistance measurement could be carried out accurately with a limited constant test current.

\section{Proposed IMProved Method of Testing}

The device under investigation determines fault location by carrying out bi-polar voltage drop measurement. A constant, limited current passes through a circuit and volt drop is measured from the near end of the cable $\left(\mathrm{V}_{\text {near }}\right)$ and the fault position and from the far end of the cable $\left(\mathrm{V}_{\text {far }}\right)$ and the fault position.

Bi-polar measurements are carried out to reduce the effect of measuring offset thermoelectric EMF [2]. To determine fault location, the volt drop measured between one end of the cable and the fault is expressed as a fraction of the total volt drop measurement across the entire cable circuit.

$$
L_{\text {Fault }}(\%)=\frac{V_{\text {near }}}{V_{\text {near }}+V_{\text {far }}}
$$

The accuracy of this calculation therefore depends on the accurate measurement of extremely low resistances.
The proposed, more accurate formula to be tested in this project involved measuring total loop resistance accurately, by using a maximum test current. The fault distance can then be expressed as a resistance measurement (near or far), as a fraction of the overall loop resistance.

$$
\text { Fault Distance }=\frac{\boldsymbol{R}_{\text {near } / \text { far }}(\Omega)}{\text { Loop Resistance }(\Omega)}
$$

Resistance measurement is calculated using circuit current and measured volt drop.

This proposed formula is based on the fact that the sheath fault location device can determine overall loop resistance accurately using a maximum initial test current. Volt drop measurement over a larger resistance has greater accuracy than volt drop measured over smaller resistance, which reduces the margin of error in calculations [3].

\section{TESTING}

Testing was initially carried out to verify the repeatability of accurate results produced by the sheath fault location device. In order for device users to develop a confidence in results produced by the machine, results must be accurate, repeatedly.

This device was then compared with test instruments described in this paper using similar fault location techniques such as volt drop measurement, to evaluate its overall accuracy. Finally, testing was carried out using a different method of sheath fault location, with the goal of improving fault location accuracy.

Testing was carried out in suitable locations, where equipment was free from third party interference and external disturbances. Laboratories were used as test sites, where room temperature remained relatively constant.

\section{Volt Drop Measurement}

To evaluate the accuracy of this device, testing was carried out to compare volt drop measurement of the fault location device, with measurements recorded by a highly accurate nanovoltmeter. The device under investigation claims a high level of performance only above a certain volt drop measurement threshold $(5 \mu \mathrm{V})$. This series of testing aimed to verify sheath fault location accuracy for volt drop measurement below this level.

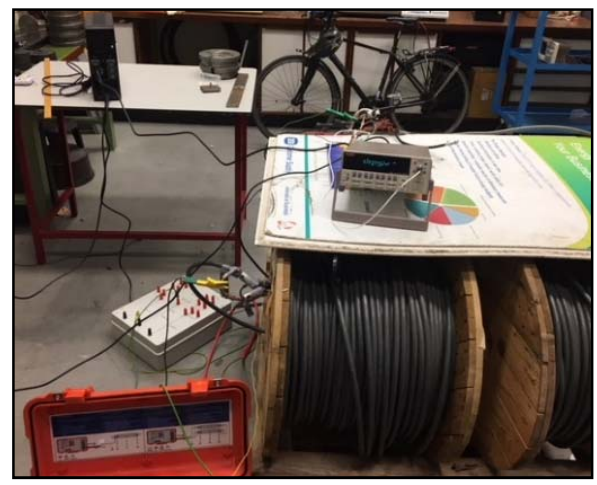

Fig. 2. Nanovoltmeter and Fault Location Device - Vold Drop Measurement 


\section{Constant Current Testing}

This testing was conducted to verify that low resistance measurements can be made using a limited constant current source. An Insulation Resistance Tester (IRT) was used where test circuit current could be maintained well below the maximum output rating of the device under investigation in this study.

Using a combination of a low constant current source and a highly accurate nanovoltmeter to measure volt drop, this testing aims to improve fault location accuracy.

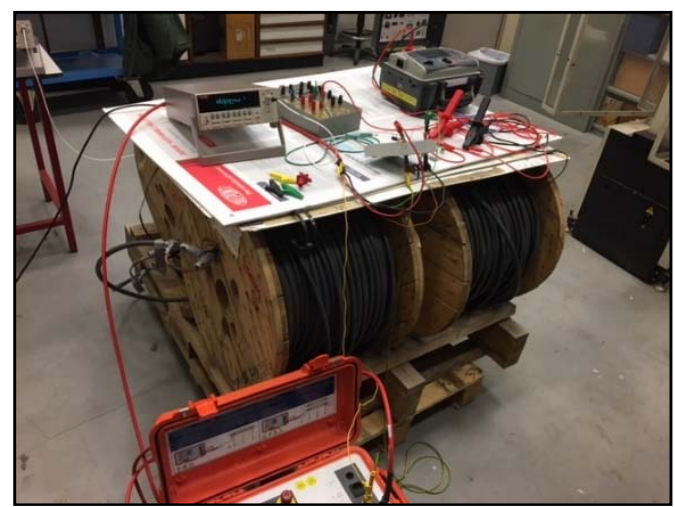

Fig. 3. Constant Current and Volt Drop Measurement

\section{Improved Method of Testing}

With a greater accuracy of loop resistance measurement, it was proposed that the accuracy of fault location will improve. Using the sheath fault location device and highly accurate nanovoltmeter, this set of testing aimed to prove that this new proposed method of testing is more accurate than methods currently in use by the device under investigation. If a greater resistance can be measured more accurately, where loop resistance is the largest resistance measurement in a cable circuit, fault location accuracy can be improved.

\section{Test Parameters}

Prior to carrying out testing, it was important to identify test parameters that would affect the accuracy of test results and keep testing as realistic as possible. These parameters included deciding on test locations where equipment could be built and remain free from any third party interference. Most importantly, test equipment needed to be isolated from earth, to reduce the effect of conduction of small leakage current to ground. Cable drums and benchmark circuits were mounted on wooden pallets.

\section{RESULTS AND ANALYSIS}

Tests were carried out to a certain standard. To carry out a thorough investigation of this device, each test was required to be repeated and most importantly, test results needed to be repeatable.

To verify the repeatability of accurate results by the sheath fault location device, testing was conducted on the $0.705 \Omega$ Benchmark Circuit representing a $1 \mathrm{~km} 25 \mathrm{~mm} 2$ cable. A $20 \mathrm{M} \Omega$ fault was placed at the $36.4 \%$ mark of this circuit. The following results were produced;

TABLE I. RESUlts Illustrating LARGE ERror ProducED By FAULT LOCATION DEVICE

\begin{tabular}{|c|c|c|c|c|c|}
\hline \multicolumn{6}{|c|}{$0.705 \Omega$ Benchmark Circuit [Near - 36.4\%][Far - 63.6\%] } \\
\hline $\begin{array}{l}\text { Voltage } \\
\text { (kV) }\end{array}$ & $\begin{array}{l}\text { Current } \\
(\mu \mathrm{A})\end{array}$ & \multicolumn{2}{|c|}{$\begin{array}{l}\text { Device Volt Drop } \\
(\mu \mathrm{V})\end{array}$} & $\begin{array}{l}\text { Result } \\
\text { (\%) }\end{array}$ & $\begin{array}{l}\text { Error } \\
\text { (\%) }\end{array}$ \\
\hline $1 \mathrm{kV}$ & 50 & $\begin{array}{l}\text { Near } \\
\text { Far }\end{array}$ & $\begin{array}{l}9.5 \\
15\end{array}$ & $37.9 \%$ & $4 \%$ \\
\hline $1.5 \mathrm{kV}$ & 75 & $\begin{array}{l}\text { Near } \\
\text { Far }\end{array}$ & $\begin{array}{l}13.5 \\
24\end{array}$ & $35.5 \%$ & $3 \%$ \\
\hline $2.5 \mathrm{kV}$ & 125 & $\begin{array}{l}\text { Near } \\
\text { Far }\end{array}$ & $\begin{array}{l}22 \\
40.5\end{array}$ & $35.4 \%$ & $3 \%$ \\
\hline $3.5 \mathrm{kV}$ & 175 & $\begin{array}{l}\text { Near } \\
\text { Far }\end{array}$ & $\begin{array}{l}31.5 \\
56.5\end{array}$ & $36.2 \%$ & $1 \%$ \\
\hline $4.5 \mathrm{kV}$ & 225 & $\begin{array}{l}\text { Near } \\
\text { Far }\end{array}$ & $\begin{array}{l}40.5 \\
72.1\end{array}$ & $35.9 \%$ & $2 \%$ \\
\hline $5 \mathrm{kV}$ & 250 & $\begin{array}{l}\text { Near } \\
\text { Far }\end{array}$ & $\begin{array}{l}45.5 \\
80\end{array}$ & $36.0 \%$ & $2 \%$ \\
\hline $6 \mathrm{kV}$ & 300 & $\begin{array}{l}\text { Near } \\
\text { Far }\end{array}$ & $\begin{array}{l}54.5 \\
96\end{array}$ & $36.1 \%$ & $1 \%$ \\
\hline \multicolumn{5}{|c|}{ Average Error } & $2.3 \%$ \\
\hline
\end{tabular}

Test voltage ranging from $1 \mathrm{kV}$ to $6 \mathrm{kV}$ was used for this test. As shown by the relatively large percentage error of $2.3 \%$ indicated in Table 4, repeatability in the fault position recorded was an issue.

Testing was carried out in the $1000 \mathrm{~m} 25 \mathrm{~mm} 2$ test circuit, where test voltage varied between $500 \mathrm{~V}$ to $7.5 \mathrm{kV}$. Fault magnitude varied from $1 \mathrm{M} \Omega$ up to $20 \mathrm{M} \Omega$, moving along the circuit at several $250 \mathrm{~m}$ intervals. A comparison was made between the sheath fault location device and the nanovoltmeter, both using volt drop measurement to determine the fault location.

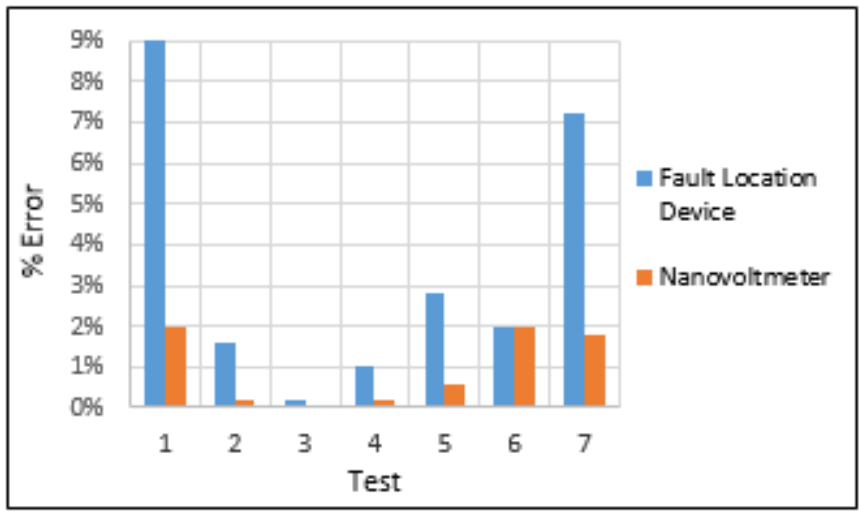

Fig. 4. Comparison of Sheath Fault Location Device and Nanovoltmeter

As shown by the results in Figure 4, the nanvoltmeter results have a much lower percentage of error in determining fault location. It is important to note that results produced by the nanovoltmeter were accurate even when volt drop measurement was less than the $5 \mu \mathrm{V}$ fault location device accuracy limitation. 
Testing was then carried out on the $0.705 \Omega 1000 \mathrm{~m}$ $25 \mathrm{~mm} 2$ test circuit, where fault distance was placed at the $25 \%$ distance along the cable. This fraction of cable resistance was measured using a constant current and a volt drop measurement from the nanovltmeter. Figure 5 indicates how accurate this low resistance measurement was, even with an extremely low test current level.

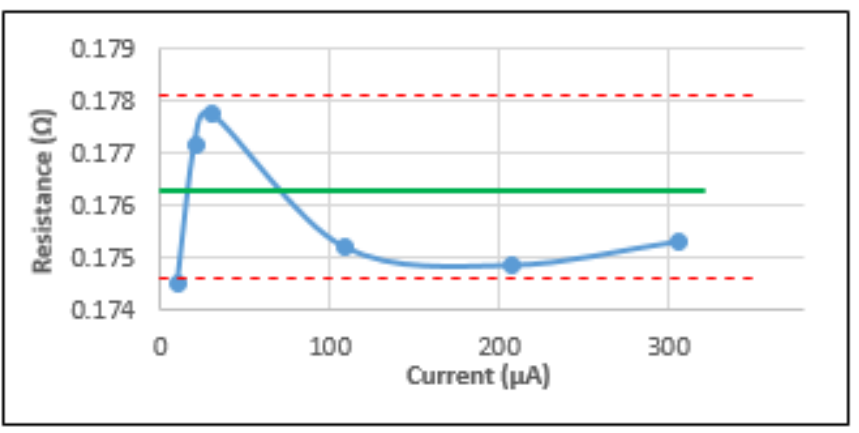

Fig. 5. $25 \%$ of Circuit Measurement using Limited Current

As shown by these results, for a $1 \mathrm{M} \Omega$ fault, location accuracy is quite good with the average percentage error determined is less than $1 \%$ (shown in red).

Finally, testing was conducted to verify the accuracy of the proposed improved method of fault location.

Testing was carried out on the $0.07 \Omega$ Benchmark Circuit, where a fault was placed at the $71.4 \%$ mark of the line and test voltage was limited to $500 \mathrm{~V}$. Based on test results from these circuits, the following comparison between the original and proposed improved fault location method was made.

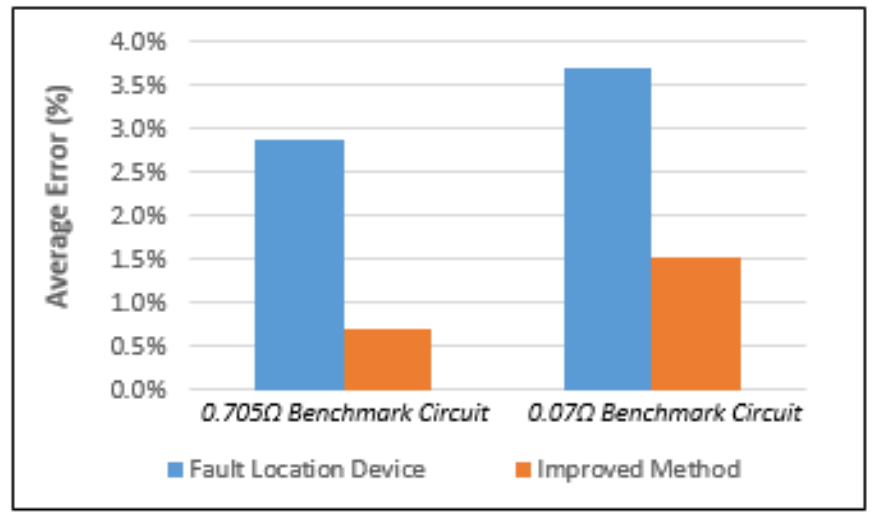

Fig. 6. Comparison of Original and Proposed Method of Improvement of Fault Location Device

The above data illustrates the difference in average error generated by both methods where clearly, improved method was found to yield a much greater accuracy of results.

\section{CONCLUSIONS}

The main aims and objectives of this study was to analyse a number of test methods for measuring the location of faults in underground cables and to determine a method of improving the accuracy of cable sheath fault pre-location. Overall these were met in the course of this project. A more accurate method of sheath fault location reflects in a reduction in maintenance and repair costs for companies including ESB Networks. Increased fault pre-location accuracy can also reduce fault-finding time and costs significantly due to reduced digging for underground cable faults.

As outlined in this paper, the fault location device has the capability of producing accurate results. However, the device was unable to reproduce accurate results consistently. This device was then compared with other test instruments, suggested to be capable of producing more accurate results repeatedly. Based on results described in this study, these instruments produced a lower percentage error in fault location.

The proposed method of fault location improvement, operated based on the principle of accurate loop resistance measurement using a limited test current as described in the thesis. Based on a series of tests undertaken during the project, this method proved to be more successful than the current method of fault location utilized by the device.

It is recommended that if further testing was to be conducted, by an independent party, it would help confirm the improvements made to sheath fault location accuracy discussed in this thesis. Also, more testing would help confirm the capabilities of the proposed improved method of testing.

It is also recommended that greater manufacturer involvement in research testing and improvement would be most beneficial. An experimental display, illustrating a method of improved accuracy of this device in the presence of manufacturer representatives would hopefully result in a modification of the device's fault location technique.

\section{REFERENCES}

[1] Benjaminsen, J.T. (2001, Oct.). "Sheath Testing of MV Polymer Cables". SINTEF Energy Research. [Handbook]. 1(1), pp. 18-35.

[2] Cigoy, D. (May, 2010). "Accurate Low-Resistance Measurements Start with Identifying Sources of Error". Keithley, A Tektronix Company. pp19.

[3] Clegg, B., Underground Cable Fault Location, 3rd ed. Hertfordshire: BCC Electrical Engineering and Training Consultancy, 2004.

[4] Harvard University. "A Summary of Error Propagation". Physical Sciences 2, vol.1, pp1-5, Autumn 2007.

[5] Horsman, D. (March, 2012) "Detecting Sheath Faults in Plastic Ducts for Voltages up to and including 132kV: Evaluation of Possible Methods". EA Technology. [Confidential Report]. pp. 3-7.

[6] Janesch, J., (May, 2013). "Two-Wire vs. Four-Wire Resistance Measurements: Which Configuration Makes Sense for Your Application". Keithley, A Tektronix Company. pp1-3.

[7] Minghua, L. \& Xu, B. "A Novel Sheath Fault Location Method for High Voltage Power Cable", in Proceedings of the $7^{\text {th }}$ International Conference on Properties and Applications of Dielectric Materials, Nagoya, 2003, pp. $20-22$

[8] Wang, Q. et al. "Fault location in the outer sheath of power cables". Journal of Power Technologies, vol.4, pp250-258, 2014 